OPEN ACCESS

Edited by:

Ruowen Zhang,

Stony Brook University, United States

Reviewed by:

Yong Zhang,

Liao Ning Cancer Hospital and

Institute, China

Dayong Yu,

Dalian University, China

*Correspondence:

Chang-lai Hao

haochanglai882@163.com

Specialty section:

This article was submitted to Molecular and Cellular Oncology,

a section of the journal

Frontiers in Oncology

Received: 03 October 2020 Accepted: 17 November 2020 Published: 23 December 2020

Citation:

Zheng H-c, Zhao S, Xue H, Zhao E-h,

Jiang H-m and Hao C-I (2020) The Roles of Beclin 1 Expression in Gastric Cancer: A Marker for Carcinogenesis,

Aggressive Behaviors and

Favorable Prognosis, and

a Target of Gene Therapy.

Front. Oncol. 10:613679.

doi: 10.3389/fonc.2020.613679

\section{The Roles of Beclin 1 Expression in Gastric Cancer: A Marker for Carcinogenesis, Aggressive Behaviors and Favorable Prognosis, and a Target of Gene Therapy}

\author{
Hua-chuan Zheng ${ }^{1}$, Shuang Zhao ${ }^{1}$, Hang Xue ${ }^{1}$, En-hong Zhao ${ }^{2}$, Hua-mao Jiang ${ }^{3}$ \\ and Chang-lai Hao ${ }^{4 *}$ \\ ${ }^{1}$ Department of Oncology and Experimental Center, The Affiliated Hospital of Chengde Medical University, Chengde, China, \\ 2 Department of Surgery, The Affiliated Hospital of Chengde Medical University, Chengde, China, ${ }^{3}$ Department of Urology, \\ The First Affiliated Hospital of Jinzhou Medical University, Jinzhou, China, ${ }^{4}$ Department of Hematology, The Affiliated Hospital \\ of Chengde Medical University, Chengde, China
}

Beclin 1 is encoded by Becn1, and plays a role in tumorigenesis, neurodegeneration, apoptosis and autophagy. Here, the aggressive phenotypes and relevant proteins were examined after Beclin 1 expression was altered in gastric cancer cells. We also observed the effects of Beclin 1 on gastric carcinogenesis using Becn 1 knockout mice. Finally, clinicopathological significances of Beclin 1 expression were analyzed using meta- and bioinformatics analyses. Becn1 overexpression was found to inhibit proliferation, glucose metabolism, migration and invasion of gastric cancer cells, whereas its knockdown caused the opposite effects. Beclin 1 suppressed the tumor growth by decreasing proliferation and increasing apoptosis. The heterozygous abrogation of Becn1 in gastric pit, parietal and chief cells could not cause any epithelial lesion. Beclin 1-mediated chemoresistance was closely linked to the autophagy, Bax underexpression, and the overexpression of Bcl-2, LRP1, MDR1, and ING5. Bioinformatics analysis showed higher Becn1 mRNA expression in intestinal- than diffuse-type carcinomas $(P<0.05)$, and in male than female gastric cancer patients $(P<0.05)$. Becn 1 hyperexpression was positively associated with both overall and progression-free survival rates of the cancer patients $(P<0.05)$. Meta-analysis showed that down-regulated Beclin 1 expression in gastric cancer was positively with lymph node metastasis, TNM staging, dedifferentiation and poor prognosis $(P<0.05)$. Becn1-related signal pathways in gastric cancer included prostate, lung, renal, colorectal, endometrial and thyroid cancers, glioma, and leukemia, the metabolism of amino acid, lipid and sugar, and some signal pathways of insulin, MAPK, TRL, VEGF, JAK-STAT, chemokine, p53, lysosome, peroxidome and ubiquitinmediated protein degradation $(P<0.05)$. These suggested that Beclin 1 might be considered as a potential marker of gastric carcinogenesis, aggressiveness and prognostic prediction, and as a target of gene therapy in gastric cancer. 


\section{INTRODUCTION}

There are a worldwide decrease in morbidity and mortality and rapid development in diagnostic and operative techniques, but gastric cancer still challenges the human health. The clinical outcome and prognosis of gastric cancer are generally worse because it has often metastasized by the time of discovery and most cancer patients are elderly at presentation $(1,2)$. Therefore, deep clarification of molecular mechanisms about gastric carcinogenesis and subsequent progression may remarkably improve early finding, diagnosis and treatment.

Autophagy is a conserved intracellular degradation pathway via autophagosomes formation, essential for protein development, homeostasis and survival, and mainly mediated by Beclin $1(3,4)$. EHMT2/G9a hypoexpression reduced $\mathrm{H} 3 \mathrm{~K} 9 \mathrm{me} 2$ level, and dissociation of EHMT2 with H3K9me2 from Becn 1 promoter, and epigenetically up-regulated Becn 1 transcription via a high ROS level and NF- $\mathrm{KB}$ activation (5). Additionally, Beclin 1 binds to Bcl-2, Bcl-w, and Bcl-xL via BH3 receptor domain by phosphorylation and ubiquitination of Beclin 1 (6). Beclin 1 is phosphorylated at ser-90 by PP2A and DAPK3 to control autophagy (7). The phosphorylated Beclin 1 at S409 by CK1 is essential for p300 binding and Beclin 1 acetylation at lysine 430 and 437 (8). RNF216 interacts with and ubiquitinates Beclin 1 at lysine 48 , thereby contributing to Beclin 1 degradation, while SLC9A3R1 and USP19 blocks ubiquitin-dependent Beclin 1 degradation by interacting with Beclin 1 and removing the K11-linked ubiquitin respectively (9, 10). Liu et al. (11) found that Beclin 1, the core molecule of the Becn1-PIK3C3 complex, could be SUMO3-conjugated by PIAS3 predominantly at K380 and deSUMOylated by SENP3. Tang et al. (12) reported that $14-3-3 \zeta$ bound to and stabilized phospho- Beclin 1(S295), and induced autophagy and chemoresistance in hepatocellular carcinoma cells. Caspase 3mediated hydrolysis of Beclin 1 suppresses autophagy or enhances apoptosis by translocating Bax to the mitochondria for the release of cytochrome $\mathrm{c}(13,14)$, whereas ABHD5 directly competes with Caspase 3 for binding to Beclin 1, and consequently prevents Beclin 1 from cleavage (15).

Previously, Beclin 1 overexpression in ovarian cancer was reported to negatively correlate with the differentiation and higher cumulative and relapse-free survival rates (16). Either Beclin 1 mRNA or protein hyperexpression was seen in colorectal and gastric cancers in comparison to precancerous lesion or mucosa. Beclin 1 expression was inversely associated with liver metastasis and distant metastasis of colorectal cancer, or venous invasion, lymph node metastasis, TNM staging, dedifferentiation and favorable prognosis of gastric cancer (17, 18). In colorectal cancer cells, Beclin 1 inhibited cell viability, migration and invasion, lamellipodia formation, and tumor growth, induced autophagy and apoptosis (19). Reportedly, Beclin 1 overexpression augmented the apoptotic induction of cis-diamminedichloroplatinum via enhancing Caspase-9 activity in gastric cancer cells (18). Gao et al. (20) reported that radiotherapy also induced autophagy and increased Beclin-1 expression via p53 pathway. Biallelic loss of Becn1 is embryonically lethal for knockout mice, and promotes spontaneous tumorigenesis of lymphomas, liver and lung cancers (21-24). Here, we analyzed the effects of Beclin 1 expression on the aggressive behaviors and phenotypes of gastric cancer cells, and clarified relevant mechanisms. To explore the role of Becn 1 knockout in gastric carcinogenesis, we established conditional Becn1 knockout mice in gastric pit, parietal and chief cells using the Capn8, Atp4b and PGC promoter to initiate Cre recombination respectively. Finally, clinicopathological significances were analyzed using meta- and bioinformatics analyses.

\section{MATERIALS AND METHODS}

\section{Cell Line and Culture}

Gastric cancer cell lines (BGC-823 and MKN28) were kindly presented by Prof. Su of Jinzhou Medical University. These cells were grown in RPMI 1640 medium containing FBS, penicillin, and streptomycin in $5 \% \mathrm{CO}_{2}$ at $37^{\circ} \mathrm{C}$. BGC-823 and MKN28 cells were subjected to pcDNA3.1-Becn1 or pcDNA3.1 vector transfection, and selected by G418 with monoclone collection. The target sequences of sh-Becn1 were 5'-CACCGGAATGGA ATGAGATTAATGCTTCAAGAGAGCATTAATCTCATT CCATTCCTTTTTTG-3' and 3'-CCTTACTTACTCT A A T T A C G A A G T T C T C T C G T A A T T A GA G T A A GGTAAGGAAAAAACCTAG-5'. Additionally, we treated cells with MG132 (proteasome inhibitor), paclitaxel (mitotic inhibitor), or SAHA (histone deacetylase inhibitor).

\section{Proliferation Assay}

We used cell counting kit-8 (CCK-8) to determine cell proliferation. In brief, $2.0 \times 10^{3}$ cells/well were cultured on 96well plate. After adhering to plate. $10 \mu \mathrm{l}$ of CCK- 8 solution was added into each well of the plate at different time points, and the absorbance was measured at $450 \mathrm{~nm}$ after $3 \mathrm{~h}$ incubation.

\section{Cell Cycle Analysis}

We trypsinized, collected, and fixed the cell using ethanol for $2 \mathrm{~h}$. After RNase treatment for $1 \mathrm{~h}$, cells were pelleted and stained by propidium iodide (PI) for $30 \mathrm{~min}$. At final, flow cytometry was used to examine PI signal.

\section{Apoptosis Assay}

FITC-labeled annexin V staining (Kagen, China) was employed to indicate phosphatidylserine externalization of early apoptosis in terms of manufacturer's instructions.

\section{Measurement of Extracellular Acidification Rate and Oxygen Consumption Rate}

We measured the metabolic parameters using wing discs of abxUbxFLPase of Seahorse metabolic flux analyzer. Discs were measured in bicarbonate-free Schneider medium with $12 \mathrm{mM}$ glutamine and $11 \mathrm{mM}$ glucose. The glycolysis can be indicated by extracellular acidification rate (ECAR), and the mitochrondrial respiration by oxygen consumption rate (OCR). We also normalized ECAR and OCR values using protein amount according to BCA assay. 


\section{Transwell Chamber Assay}

To assess invasion, we cultured $2.0 \times 10^{5}$ cells in FBS-free medium in the matrigel-coated insert on the chamber top, and added 10\%-FBS-containing medium to the chamber bottom as a chemoattractant. After 24-h incubation, the upper member of insert was scrubbed, and the lower portion fixed in methanol and followed by Giemsa dye. To measure migration, we repeated the above-mentioned protocol excluding membrane-control insert.

\section{Animals}

We housed three mice per plastic cage with paper chips, standard rodent food and water in pathogen-free and temperaturecontrolled condition with a 12-h light/dark illumination cycle. All animal experiments were conducted using protocols approved by the Committee on Animal Experimentation of The Affiliated Hospital of Chengde Medical University. Female 8 -week Balb/c nude mice were used for subcutaneous implantation by injection of $2.0 \times 10^{6}$ cells per mouse to axilla ( $\mathrm{n}=10 \mathrm{mice} /$ group). Finally, the mice were anesthetized, photographed, and killed for tissue sampling. The part of tumors was subjected to routine pathological block preparation, and the remaining was stored in liquid nitrogen until protein, RNA or protein extract. The tumor volume was calculated as width ${ }^{2} \times$ length $\times 0.52$.

Additionally, we performed cre-mediated deletion of floxed alleles by mating Becn 1 conditional mutant mice (Mouse Biology Program, University of California, Davis USA) with Capn8-cre, Atp4b-cre (kindly presented by Prof. Yang) or PGC-cre (prepared in our Lab., unpublished) transgenic mice. At least 5 mice were killed at 9 month, and their stomachs were analyzed.

\section{DNA Analysis}

DNA was extracted from mouse tail and stomach using phenolchloroform method. We performed genotyping by PCR. The PCR primer sequences were CSD-lacF: 5'-CTACCATTA CCAGTTGGTCT GGTGTC-3', CSD-neoF: 5'-GGGATCTCA TGCTGGAGTTCTTCG-3', CSD-Becn 1 -F: 5'-TTGTAC CGTGATTTAGGGCGTTTGC-3', CSD-Becn 1-R: 5' CAGAGTGAGTTCCAAGACAGCCAGG-3', CSD-Becn1-ttR: 5'-CTCCCAAGTGCTGGGATTAAAGACG-3' and cre: 5'GCCTGCATTACCGG TCGATGC-3' and 5'-CAGGGTGT TATAAGCAATCCC-3'. The truncated Becn1 and cre were confirmed by the tail DNA PCR. The deletion of Becn1 was confirmed by PCR amplification of gastric mucosa DNA.

\section{Real-Time RT-PCR}

We extracted total RNA from cells or tissues using Trizol (Takara). Reverse transcription of $1 \mu \mathrm{g}$ RNA was performed using random primers and AMV reverse transcriptase. PCR primers were designed according to the sequences in GenBank. Oligonucleotide primers for PCR were 5'-TTACCACAGC CCAGGCGA-3' and 5'-GCCACCATCAGATGCCTC-3' for mouse Becn1, and 5'-ACATACTCAG CACCGGCCTC-3' and 5'-TATGACTCCACTCACGGCAAA-3' for mouse GAPDH. SYBR Premix Ex Taq II kit (Takara) was employed to amplify target cDNAs using GAPDH as an internal control.

\section{Western Blot}

Protein was extracted in RIPA lysis buffer and determined by BCA assay. We separated denatured protein in SDSpolyacrylamide gel and transferred to Hybond membrane. After blocked in 5\% skim milk, the membranes were incubated with primary antibodies (Table 1) and then with anti-rabbit, or anti-mouse IgG conjugated to horseradish peroxidase (Dako). We visualized bands using ECL-Plus detection reagents.

\section{Histological Analysis}

Tissues block were sectioned and consecutive $5 \mu \mathrm{m}$-thick sections were stained with HE, alcian blue, PAS and HID. Sections were deparaffinized, dehydrated, and subjected to immunostaining using primary antibodies (Table 1) as previously described (17), or TUNEL using ApopTag Plus Peroxidase In Situ Apoptosis Detection Kit (Millipore) as reported (19).

\section{Identification of Eligible Studies}

We searched the articles using BIOSIS, PubMed, SciFinder, and Web of Science until July 10, 2020. The following strategy was (Becn1 OR Beclin 1) AND (stomach OR gastric) AND (adenocarcinoma OR carcinoma OR cancer). The articles were included to observe Beclin 1 immunostaining in gastric cancers and compare Beclin 1 expression with their pathobiological features and prognosis. We excluded the abstract, comment, review and meeting, and papers about Western blot, RT-PCR, cDNA chip, or transcriptomic data for Beclin 1 expression.

\section{Data Extraction and Quality Score Assessment}

Both reviewers independently collected useful information from all eligible articles, including first author, publication year,

TABLE 1 | The antibodies used in the present study.

\begin{tabular}{|c|c|c|}
\hline Name & Source & Company \\
\hline Beclin 1 & Rabbit & Santa Cruz \\
\hline$\beta$-actin & Mouse & Santa Cruz \\
\hline GAPDH & Rabbit & Wanleibio \\
\hline LC3B & Rabbit & Wanleibio \\
\hline Bax (B-9) & Mouse & Santa Cruz \\
\hline $\mathrm{Bcl}-2$ (C-21) & Rabbit & Santa Cruz \\
\hline Akt & Rabbit & Santa Cruz \\
\hline PI3K & Rabbit & Abcam \\
\hline p-p38 & Rabbit & Santa Cruz \\
\hline P38 & Rabbit & Santa Cruz \\
\hline$N F-\kappa B$ & Rabbit & CST \\
\hline Cdk4(C-22) & Rabbit & Santa Cruz \\
\hline E-cadherin & Mouse & Abcam \\
\hline Twist1 & Rabbit & Abcam \\
\hline Zeb2(E-11) & Mouse & Santa Cruz \\
\hline$\beta$-catenin & Rabbit & Abcam \\
\hline MRP1 & Mouse & Abcam \\
\hline GST $\pi$ & Rabbit & Abcam \\
\hline MDR1 & Rabbit & Abcam \\
\hline FBXW7 & Rabbit & Wanleibio \\
\hline LRP1 & Rabbit & Abcam \\
\hline ING5 & Rabbit & Proteintech \\
\hline CD147 & Rabbit & Abcam \\
\hline
\end{tabular}


ethnicity, country, histological subtypes, control source, antibody company, numbers of cases and controls, and survival times. Engauge Digitizer software was employed to mine information from Kaplan-Meier curves and calculate Hazard ratios. We discussed to resolve disagreement until consensus. Publication quality was evaluated according to Newcastle Ottawa Scale.

\section{Bioinformatics Analysis}

The transcriptomic and clinicopathological data of gastric cancer patients were downloaded from TCGA database by TCGA-assembler of $\mathrm{R}$ software. We analyzed Becn1 mRNA level between gastric normal and cancer tissues using Oncomine and TACGA data. Becn1 expression was compared with clinicopathological and prognostic data of gastric cancer patients. GSEA was performed with GSEA-3.0. We used Becn1 level as a phenotype label and analyzed pathway enrichment. Kaplan- Meier plotter was employed to analyze the prognostic significance of Becn1 mRNA.

\section{Statistics Analysis}

We used Revman software 5.3 to carry out Meta-analysis, and evaluated HWE using Chi-square test. If there was no significant heterogeneity, the fixed effect model would be employed. Experimental and TCGA data was handled with SPSS 10.0 software using t test or survival analysis. We regarded $P<0.05$ as statistically significant.

\section{RESULTS}

\section{The Effects of Beclin 1 Overexpression on the Aggressiveness of Gastric Cancer Cells}

Beclin 1 was successfully overexpressed in BGC-823 and MKN28 cells according to real-time RT-PCR and Western blot (Figure 1A, $P<0.05)$. Beclin 1 overexpression suppressed the proliferation of both cancer cells, evidenced by CCK-8 (Figure 1B, $P<0.05$ ). Becn1 transfectants showed the chemoresistance to MG132, paclitaxel and SAHA at both time- and dose-dependent manners (Figure 1C, $P<0.05)$. After transfected with Becn1-expressing plasmid, the appearance of gastric cancer cells became irregular, vacuolar, polynucleate and protrudent (Figure 1D). Flow cytometry showed $G_{1}$ or $S$ arrest, and apoptotic induction in Becn 1 transfectants of gastric cancer cells (Figures 1E, F, $P<0.05$ ). Beclin 1 overexpression decreased glycolysis and following mitochondrial oxidization, cell migration and invasion according to oxygen consumption and transwell assays respectively (Figures $\mathbf{1 G}, \mathbf{H}$, $P<0.05)$. As shown in Figure 1I, Becn1 overexpression up-regulated the expression of LC-3B, Bax, Akt, p-Akt, PI3K, p-PI3K, Ecadherin, GST- $\pi$, MDR1, LRP1, ING5 and CD147, but downregulated the expression of Bcl-2, p38, p-p38, NF- $\mathrm{kB}$, Twist, Zeb2 and $\beta$-catenin. There was no difference in the expression of Cdk4 and MRP1 between gastric cancer cells and their Becn1 transfectants.

Becn1 was successfully silenced in SGC-7901 cells, evidenced by real-time RT-PCR (Figure 2A, $P<0.05$ ) and Western blot (Figure 2B, $P<0.05)$. Becn1 knockdown promoted the cell viability
(Figure 2C, $P<0.05$ ) and the chemosensitivity against MG132, 5FU, and SAHA (Figure 2D, $P<0.05$ ), induced $S$ phase progression (Figure 2E, $P<0.05$ ), and inhibited the apoptosis (Figure $2 \mathbf{F}$, $P<0.05)$. Down-regulated Becnl expression promoted migration and invasion according to transwell chamber assay (Figure 2G). Becn 1 knockdown decreased the expression of p-Akt, p-PI3K, LC3B, E-cadherin, MRP1, MDR1, LRP1 and ING5, but increased the expression of Bcl-2, Akt, PI3K, p-p38, Cdk4, Zeb2, and $\beta$-catenin. No alteration was observed in the expression of GST $-\pi$, NF- $\kappa$ B and CD147 (Figure 2H).

Moreover, Beclin 1 overexpression suppressed tumor growth of gastric cancer cells in nude mice (Figure 3A, $P<0.05$ ). There was a higher Beclin 1 expression, a stronger signal of TUNEL and a weaker ki-67 expression in tumors of Becn1-overexpressing BCG-823 (Figures 3B, C). Beclin 1 down-regulated the expression of VEGF, E-cadherin, Bcl-2, but up-regulated the expression of LC-3B, NF- $\kappa \mathrm{B}$, $\mathrm{PI} 3 \mathrm{~K}, \mathrm{Akt} 1 / 2 / 3$ and MDR in xenograft tumor of gastric cancer cells (Figure 3C). Moreover, we matched the conditional Becn1-knockout (KO) mice with Atp4b-cre, Capn8-cre or PGC-cre mice, and designed the primers to confirm the monoallelic deletion of Becn1 using DNA from tail and gastric mucosa (Figure 4A). According to PCR results, we obtained the monoallelic deletion of Becnl in gastric mucosa in Becn1-PGC-cre, Becn1-Capn8-cre and Becn1-Atp4b-cre mice (Figure 4B). There was a weaker expression of $B e c n 1$ in gastric epithelium of Becn1-PGC-cre, Becn1-Capn8-cre and Becn1-Atp4bcre than those of wild-type (WT) mice at both mRNA and protein levels (Figure 4C, D). However, no remarkable lesions were observed in the gastric mucosa of these three kinds of mice although weaker Beclin 1 was immunohistochemically observed in gastric chief, pit and parietal cells of Becn1-PGC-cre, Becn1-Capn8-cre, and Becn1Atp4b-cre than those of WT mice (Figures 4E-G). Additionally, there were no differences in sialic acid, neutral and sulfuric acid mucus between conditional $\mathrm{KO}$ and WT mice according to alcian blue, PAS and HID staining (Figure $\mathbf{4 H}$ ).

\section{Characteristics of Eligible Studies}

We retrieved fifteen articles about the relationship between Beclin 1 expression and cancer risk, clinicopathological or prognostic features of gastric cancer for meta-analysis (Table 2). Five pieces of paper had the samples of normal gastric mucosa and cancer $(18,28,31,35,37)$. In 12 articles, Beclin 1 expression was compared with age, invasive depth, lymph node involvement, TNM staging and Lauren's classification (18, 2537). Ten pieces of paper described the prognostic significance of Beclin 1 expression $(18,25-27,30-34,36)$.

\section{Association Between Beclin 1 Expression and Clinicopathological Parameters of Gastric Cancer}

We collected 986 cancers and 786 controls and found downregulated Beclin 1 expression in gastric cancer (Figure 5A, $P=0.02$ ). As shown in Figure $\mathbf{5 B}$, there was no difference in Beclin 1 expression between age $>60$ year and $<60$ year cancer patients $(P>0.05)$, between male and female ones (Figure 5C, $P>0.05$ ) or between $\mathrm{T}_{1-2}$ than $\mathrm{T}_{3-4}$ gastric cancer (Figure $5 \mathrm{D}$, $P=0.19$ ). Beclin 1 expression was negatively associated with lymph 

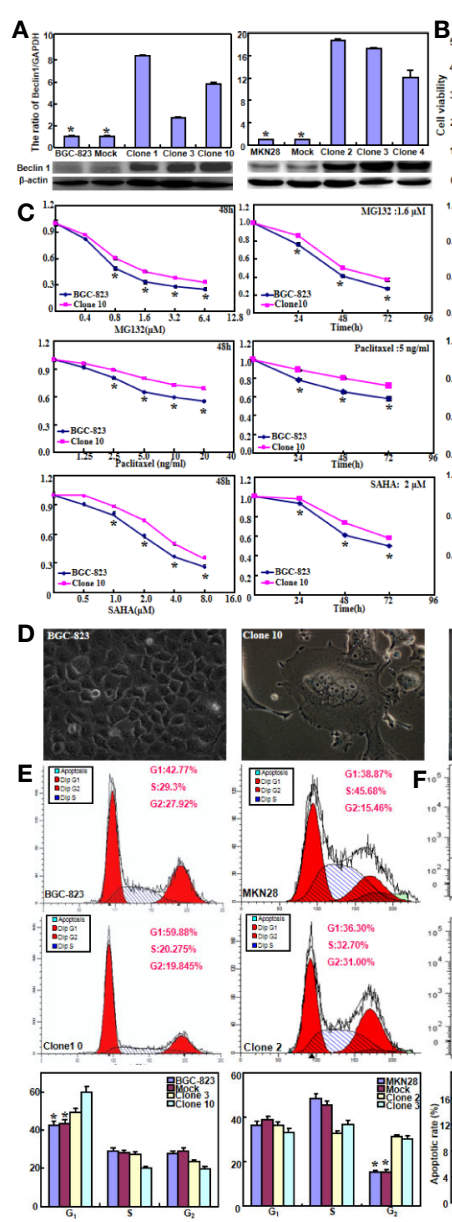
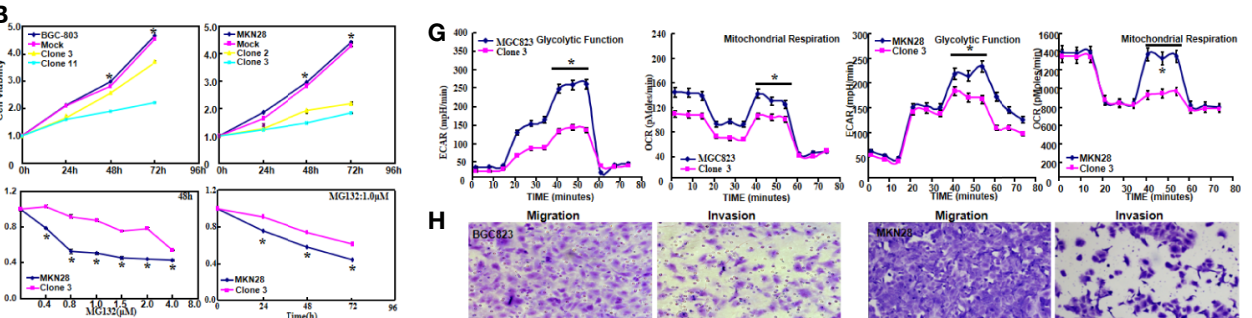

\section{Clon}
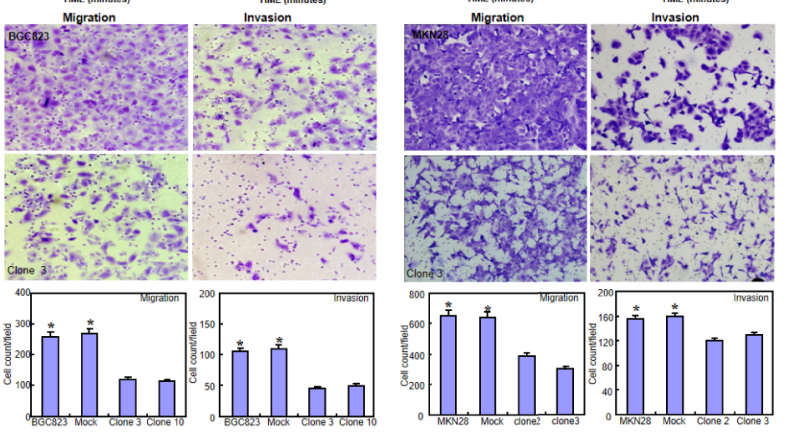

I
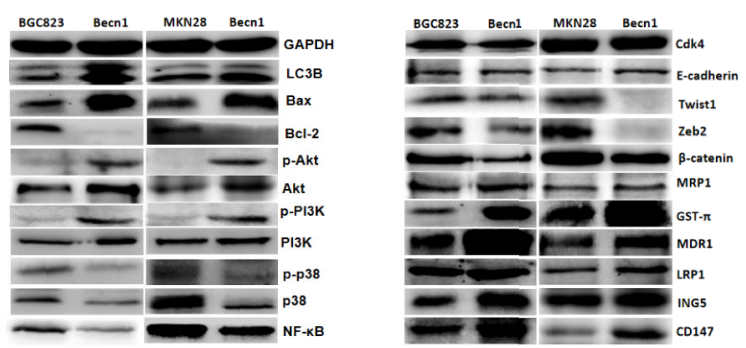

FIGURE 1 | The effects of Beclin 1 expression on aggressiveness of gastric cancer cells. Beclin 1 expression in BGC-823 and MKN28 cells was examined after transfection with pcDNA3.1-Becn1 by real-time RT-PCR and Western blot (A). The transfectants showed a decrease in growth (B) and chemosensitivity to MG132, Paclitaxel and SAHA (C) in comparison with the control or mock. After Becn1 was overexpressed, the morphological appearance was observed under microscope (D). Flow cytometry showed that Beclin 1 expression induced the $\mathrm{G}_{1}$ arrest of BGC-823 cells, but S arrest of MKN28 cells (E). Apoptosis was increased by Beclin 1 overexpression, as evidenced by Annexin $\vee$ assay (F). Oxygen consumption and transwell assays were used to monitor the glucose metabolism, migration and invasion of gastric cancer cells respectively $(\mathbf{G}, \mathbf{H})$. The phenotype-related proteins were screened by Western blot (I). ${ }^{*} P<0.05$, compared with the transfectants.

node involvement (Figure 5E, $P=0.03$ ), TNM staging (Figure 5F, $P=0.03$ ), and dedifferentiation (Figure 5G, $P=0.01$ ). Wellmoderately adenocarcinoma had a higher Beclin 1 expression than the poorly-differentiated subtype (Figure 5H, $P=0.0004$ ). As indicated in Figure 5I, there was significant association between Beclin 1 expression and favorable overall survival in patients with gastric cancer $(\mathrm{OR}=1.34$, 95\% CI: $1.15-1.56, P=0.0002)$. Sensitivity analysis was performed to evaluate individual study's influence on the pooled results by deleting one single study (data not shown).

\section{The Clinicopathological and Prognostic Significances of Becn1 Expression in Gastric Cancer}

According to TCGA databases, Becn1 mRNA expression was found to be lower in gastric cancer than normal mucosa (Figure 6A, $P<0.05)$. There was a higher Becn 1 mRNA expression in intestinal- than diffuse-type adenocarcinoma according to
DErricodata (Figure 6B, $P<0.05$ ). In TCGA data, Becn 1 expression was higher in male than female cancer patients (Figure 6C, $P<0.05)$. According to Kaplan-Meier plotter, Becn1 expression was found to positively correlate with overall and progression-free survival rates of all cancer patients (Figure 6D, $P<0.05)$, even stratified by Lauren's classification, TNM staging and treatment (Table 3, $P<0.05)$. Female, male, T2, T3, N1-N3, M1, M0 and Her-2-negative cancer patients with high Becn 1 mRNA expression had a high overall survival rate than those with its low expression $(P<0.05)$, while it was the same for progression-free survival rate in the male, T2, T4, N1-3, N1, M0, Her2-negative and -positive cancer patients $(P<0.05)$.

\section{Becn1-Related Signal Pathways in Gastric Cancer}

As summarized in Table 4, we conducted a GSEA to analyze Becn1-related signal pathways in gastric cancer. The significant 

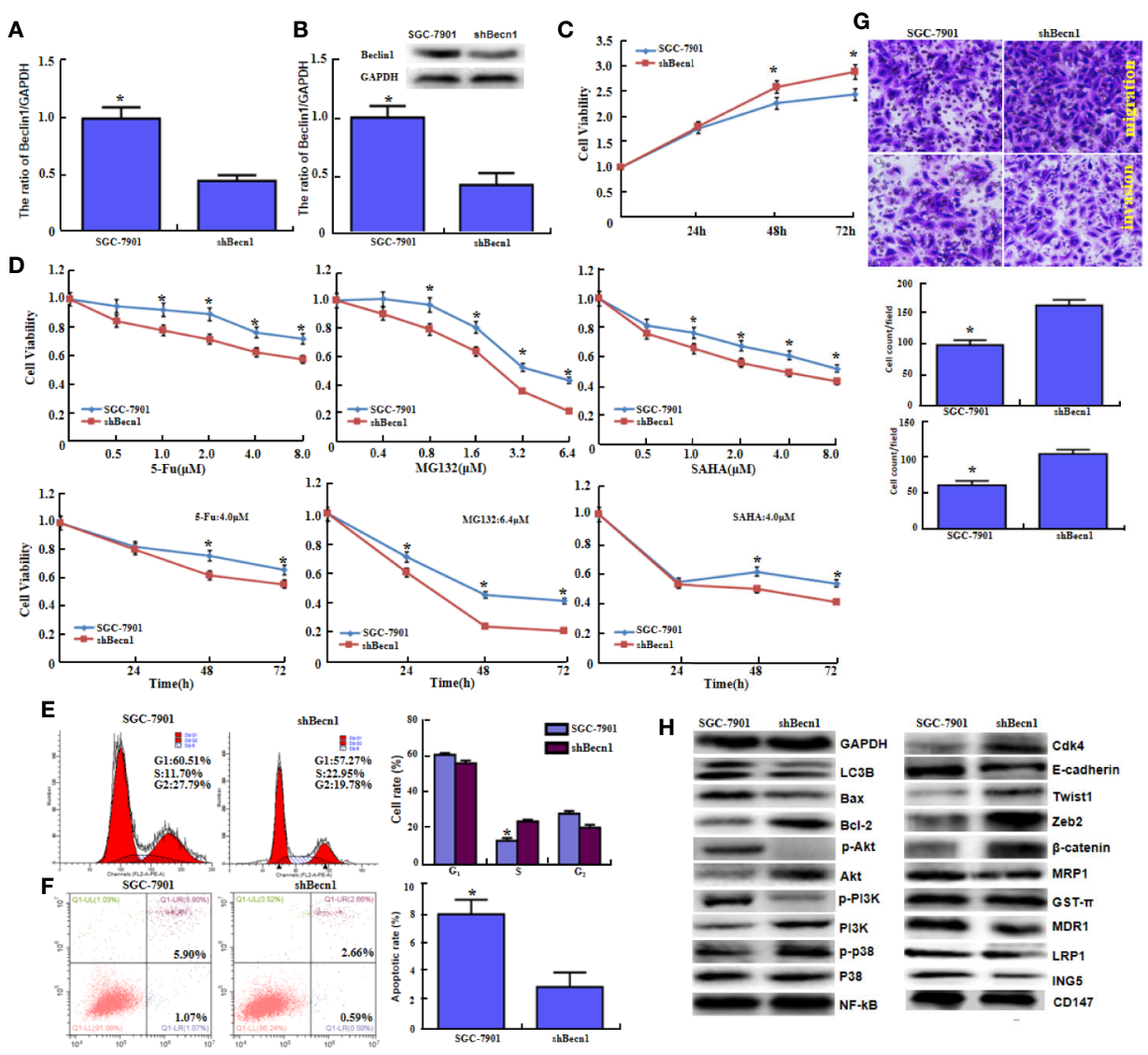

FIGURE 2 | The in vitro and in vivo effects of Beclin 1 silencing on aggressive phenotypes of gastric cancer cells. After transfection of shRNA-Becn1, its expression became weak in SGC-7901 cells by real-time RT-PCR (A) and Western blot (B). The cell viability was measured in SGC-7901 cells and their shBecn1 transfectants using CCK-8 kit (C), even treated with 5-FU, MG132, and SAHA (D). Cell cycle and apoptosis were examined by propidium iodide (PI) (E) and Annexin-V (F) staining respectively. Both migration and invasion were determined in SGC-7901 and shBecn1 transfectants by transwell chamber assay (G). The phenotype-associated proteins were screened by Western lot $\mathbf{( H )}$. ${ }^{*} P<0.05$, compared with the transfectants.

enriched pathways included prostate, lung, renal, colorectal, endometrial, thyroid cancers, glioma, and leukemia, the metabolism of amino acid, lipid and sugar, and some signal pathways of insulin, MAPK, TRL, VEGF, JAK-STAT, chemokine and $\mathrm{p} 53$, lysosome, peroxidome and ubiquitin-mediated protein degradation $(P<0.05)$.

\section{DISCUSSION}

Beclin 1 expression was reported to cause apoptosis via Bax activation and $\mathrm{Bcl}-2$ suppression in HeLa cells, inhibited proliferation and increased the chemosensitivity to Taxol (38). In lung cancer cells, Beclin 1 induced apoptosis and weakened invasion by up-regulating ECRG4 (39). In breast cancer cells, Beclin 1 overexpression improved cellular autophagy, inhibited cell proliferation, decreased cell apoptosis, mediated $G_{1}$ arrest and promoted epithelial-mesenchymal transition (EMT) via Wnt/ $\beta$ - catenin pathway (40), but Becn1 knockdown induced EMT by via posttranscriptional up-regulation and stabilization of Zeb1 mRNA (41). RelA-mediated Becn1 expression was essential for ROS-induced autophagy in oral cancer cells irradiated by laser (42). Hasan et al. (43) found that HSP90 inhibitor (Gedunin) suppressed interaction between Hsp90: Beclin-1:Bcl-2, finally to inhibit autophagosome formation (Beclin-1, Atg5-12 complex, and LC3). Hu et al. (44) observed that Becn 1 knockdown markedly promoted motility and invasion of colorectal cancer cells with STAT3 phosphorylation via the interaction between STAT and JAK2. Cheng et al. (45) found that Beclin 1 increased the migration of non-small cell lung cancer cells via interaction with Vimentin, followed by its K48-linked ubiquitination via ubiquitin-specific peptidase 14 . Here, Beclin 1 was demonstrated to suppress proliferation, migration, invasion and tumor growth, and induce cell cycle arrest, apoptosis, autophagy and chemoresistance in gastric cancer cells, whereas versa for Becn1-silencing cells, suggesting that Beclin 1 can be used as a gene therapy target of gastric cancer if its chemoresistant induction could be avoided or alleviated. Additionally, gastric lesions were not observed from monoallelic conditional KO mice of Becn1 in pit, parietal and chief cells 
A

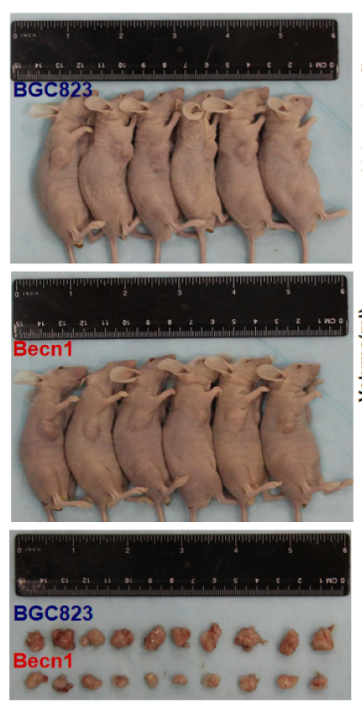

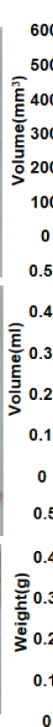

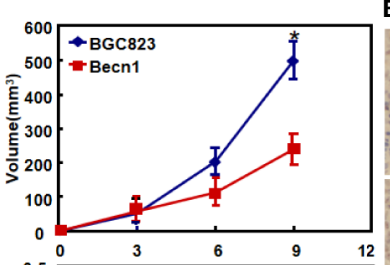

B $\quad$ BGC823

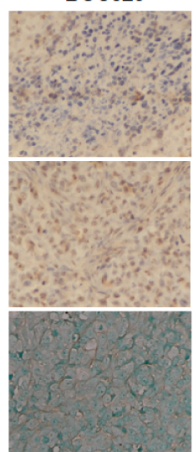

C BGC823 Becn1

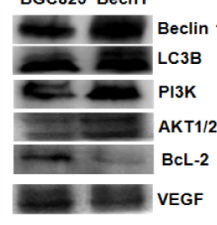

Becn1

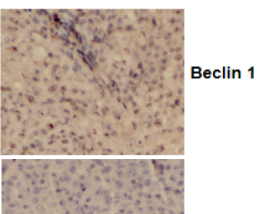

Ki-67

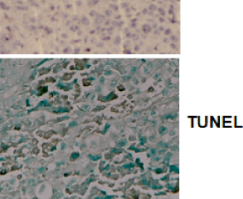

BGC823 Becn1

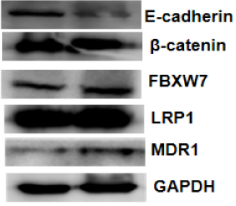

FIGURE 3 | The effects of Becn1 expression on tumor growth of gastric cancer. The growth of gastric cancer cells was faster and heavier than their Becn1 transfectants by gross appearance, and measuring tumor volume and weight $[(\mathbf{A}), P<0.05]$. The transfectant cells showed stronger signals of Beclin 1 and apoptosis than the control in subcutaneous tumor, but versa for ki-67 immunoreactivity (B). The phenotype-related proteins were screened using xenograft tumor tissues by Western blot (C). ${ }^{\star} P<0.05$, compared with the transfectant.

A

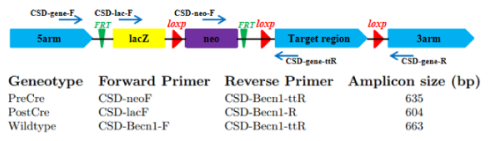

B. WT PGbe Cabe tbbe NC

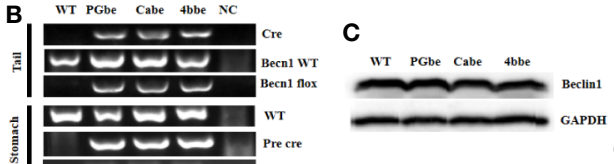

1

$\mathbf{D}_{1.2}$

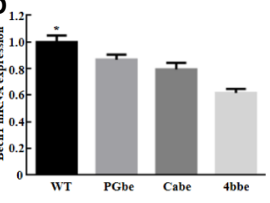

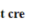
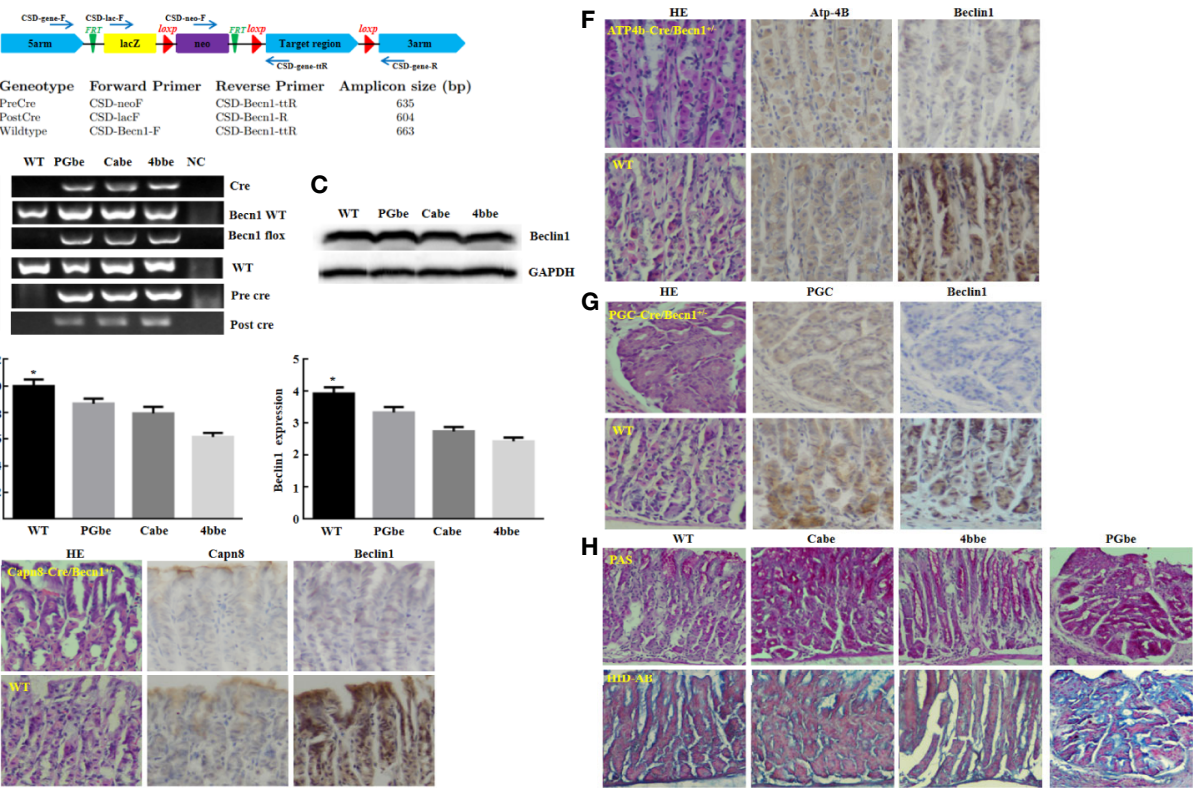

FIGURE 4 | The effects of Becn1 expression on gastric carcinogenesis. PCR primers were designed (A) and subjected to PCR of tail and stomach DNA (B) Monoallelic deletion of Becn1 was confirmed by real-time PCR (C) and Western blot (D), and couldn't cause any gastric lesions although Beclin 1 expression was reduced with Capn8, Atp-4B, and PGC immunoreactivity as control according to HE and immunohistochemistry (E-G). There was no difference in alcian blue, PAS and HID staining between three conditional knock-out mice and wild-type mice $\mathbf{( H )}$. ${ }^{*} P<0.05$, compared with the knockout mice. WT, wild-type mice; Cabe, Capn8-cre +; Becn1 +/-; 4bbe, Atp-4b-cre +; Becn1 +/-; PGbe, PGC-cre +; Becn1 +/-. 
TABLE 2 | Main characteristics of eligible studies.

\begin{tabular}{|c|c|c|c|c|c|c|c|c|c|}
\hline First author & Year & Country & Ethnicity & Antibody Source & Cases & Ctr & Risk & Outcome & Quality \\
\hline Yu M (18) & 2013 & China & Asian & Sigma & 565 & 586 & & Pos & 9 \\
\hline Geng QR (26) & 2012 & China & Asian & Novus Biologicals & 271 & & Up & Pos & 8 \\
\hline Fei BY (28) & 2016 & China & Asian & Abcam & 75 & 75 & & & 9 \\
\hline Qin WJ (29) & 2015 & China & Asian & Abcam & 156 & & & & 8 \\
\hline Zhou WH (30) & 2012 & China & Asian & Santa Cruz & 153 & & Down & Pos & 8 \\
\hline Qiu GL (33) & 2016 & China & Asian & Abcam & 96 & 96 & Up & $\mathrm{Neg}$ & 9 \\
\hline Cao QH (34) & 2016 & China & Asian & Cell Signaling & 352 & & Down & Pos & 8 \\
\hline Huang JL (35) & 2016 & China & Asian & CST & 120 & 120 & Down & & 9 \\
\hline $\mathrm{Hu}$ YF (36) & 2017 & China & Asian & abcam & 120 & 120 & Up & Pos & 9 \\
\hline Guo CQ (37) & 2010 & China & Asian & Santa cruz & 62 & 36 & Down & & 8 \\
\hline
\end{tabular}

Crt, control; Down, down-regulated; Up, up-regulated; Pos, positive, Neg, negative.

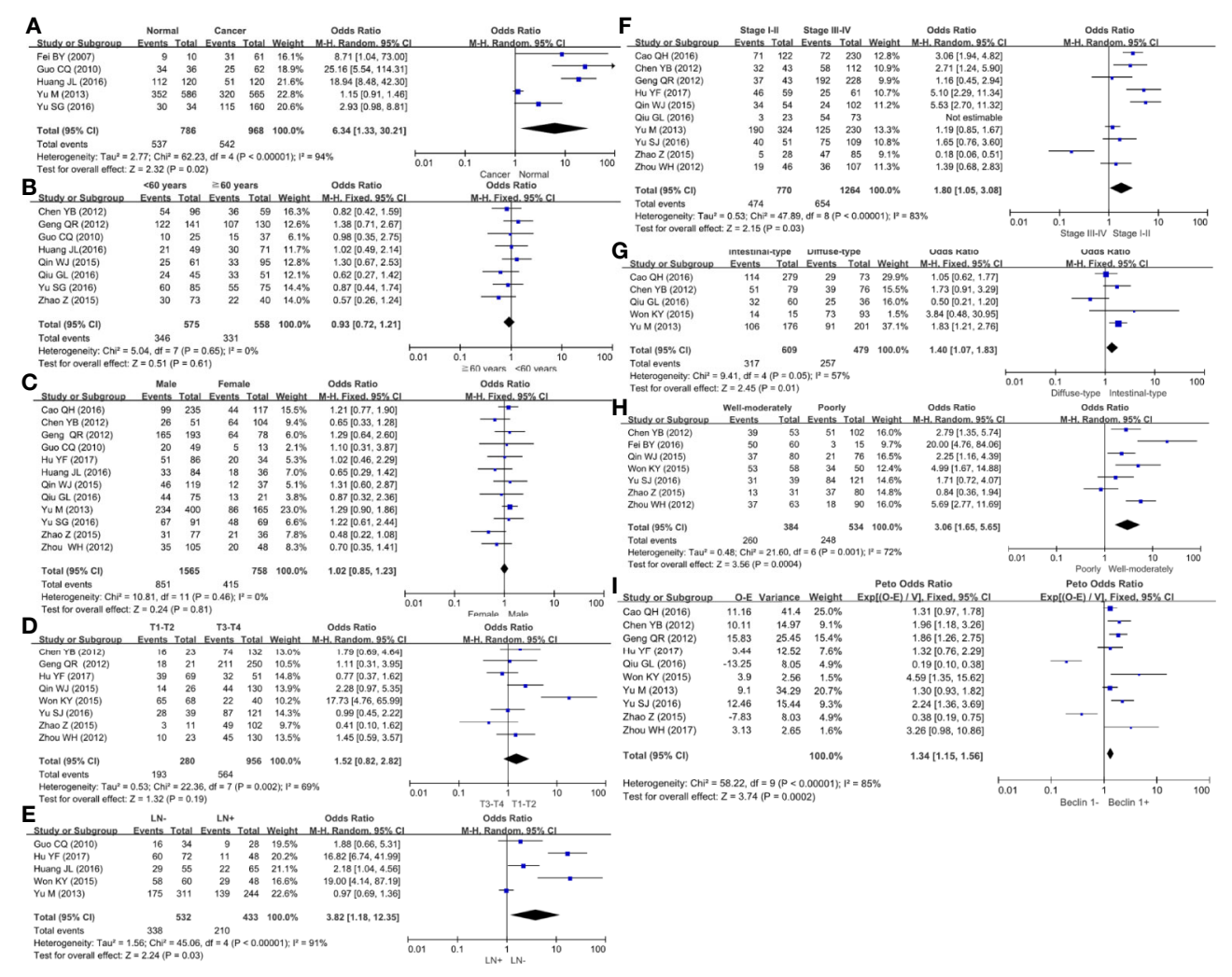

FIGURE 5 | Forest plot for the relationship between Beclin 1 expression and clinicopathological parameters of gastric cancer. (A) gastric carcinogenesis (cancer vs

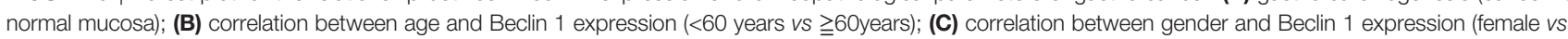
male); (D) correlation between T staging and Beclin 1 expression (Tis-1 vs T2-4); (E) correlation between lymph node metastasis (LN) and Beclin 1 expression (LNvs LN+); (F) correlation between TNM staging and Beclin 1 expression (stage I-II vs II-IV); (G) correlation between Lauren's classification and Beclin 1 expression (intestinal-type vs diffuse-type); (H) correlation between WHO' classification and Beclin 1 expression (Well-moderately differentiated vs poorly-differentiated); (I) correlation between prognosis and Beclin 1 expression (Beclin 1- vs Beclin 1+). 

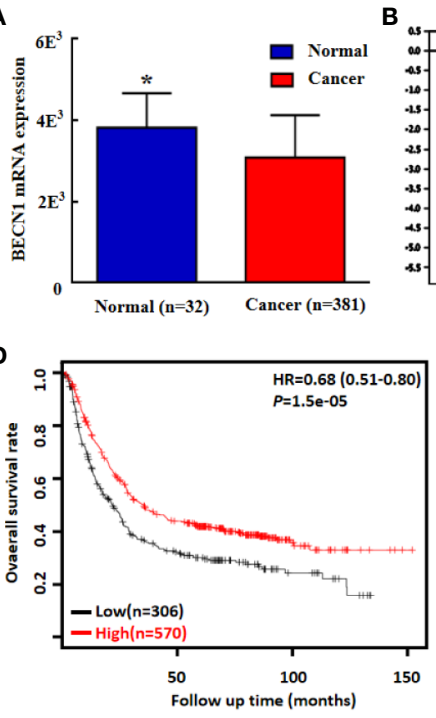

C

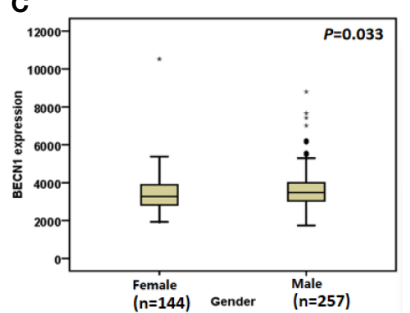

D

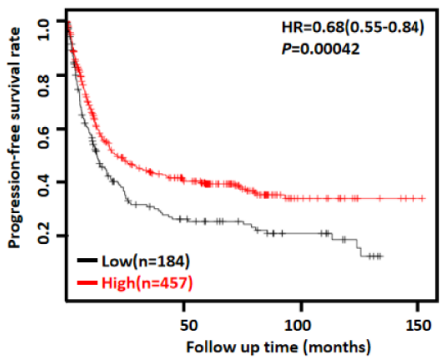

FIGURE 6 | Becn1 mRNA expression in gastric carcinogenesis and subsequent progression. A lower Becn1 mRNA expression was detectable in gastric cancer than that in normal gastric mucosa according TCGA data [(A), $P<0.05]$. There was Becn1 overexpression in intestinal-type than diffuse-type carcinoma according to DErrico's database [(B), $P<0.05]$. TCGA database showed a higher Becn1 mRNA expression in male than female patients with gastric cancer [(C), $P<0.05]$. According to the data from Kaplan-Meier plotter, Becn1 mRNA expression was positively related to both overall and progression-free survival rates of the patients with gastric cancer [(D), $P<0.05]$. HR, hazard ratio. ${ }^{*} P<0.05$, compared with the cancer.

TABLE 3 | The prognostic significance of Becn1 mRNA in gastric cancer by Kaplan-Meier plotter.

\begin{tabular}{|c|c|c|c|c|}
\hline Clinicopathological features & \multicolumn{2}{|c|}{ Overall survival } & \multicolumn{2}{|c|}{ Progression-free survival } \\
\hline \multicolumn{5}{|l|}{ Sex } \\
\hline Male & $0.61(0.49-0.75)$ & $5.1 e-06$ & $0.61(0.48-0.77)$ & $3.7 e-05$ \\
\hline \multicolumn{5}{|l|}{$\mathrm{T}$} \\
\hline 2 & $0.59(0.37-0.94)$ & 0.025 & $0.59(0.38-0.92)$ & 0.019 \\
\hline \multicolumn{5}{|l|}{$\mathrm{N}$} \\
\hline 0 & $1.73(0.73-4.1)$ & 0.21 & $1.77(0.75-4.17)$ & 0.19 \\
\hline $1-3$ & $0.53(0.4-0.69)$ & $2 e-06$ & $0.6(0.46-0.78)$ & $8.1 \mathrm{e}-05$ \\
\hline 1 & $0.35(0.22-0.55)$ & $2.3 e-06$ & $0.38(0.25-0.59)$ & $6.1 \mathrm{e}-06$ \\
\hline 2 & $0.52(0.33-0.82)$ & 0.0047 & $0.66(0.42-1.03)$ & 0.066 \\
\hline 3 & $0.56(0.32-0.98)$ & 0.039 & $0.61(0.36-1.06)$ & 0.077 \\
\hline \multicolumn{5}{|l|}{ Lauren's classification } \\
\hline Intestinal-type & $0.56(0.4-0.77)$ & 0.00039 & $0.69(0.48-0.98)$ & 0.04 \\
\hline Diffuse-type & $0.55(0.38-0.79)$ & 0.0011 & $0.57(0.4-0.83)$ & 0.003 \\
\hline \multicolumn{5}{|l|}{ Her-2 positivity } \\
\hline- & $0.65(0.52-0.81)$ & 0.00016 & $0.65(0.5-0.84)$ & 0.00088 \\
\hline+ & $0.77(0.59-1)$ & 0.051 & $0.7(0.5-0.99)$ & 0.043 \\
\hline \multicolumn{5}{|l|}{ Treatment } \\
\hline Surgery alone & $0.66(0.48-0.91)$ & 0.01 & $0.72(0.53-0.97)$ & 0.03 \\
\hline 5-FU-based adjuvant & $1.68(1.18-2.39)$ & 0.0034 & $1.66(1.17-2.35)$ & 0.0044 \\
\hline
\end{tabular}


TABLE 4 | Becn1-enriched signal pathway in gastric cancer according to the KEGG analysis.

\begin{tabular}{|c|c|c|}
\hline Name & Size & $P$ value \\
\hline Phosphatidylinositol signaling system & 76 & $<0.001$ \\
\hline Inositol phosphate metabolism & 54 & $<0.001$ \\
\hline Endocytosis & 178 & $<0.001$ \\
\hline Amyotrophic lateral sclerosis & 52 & $<0.001$ \\
\hline Insulin signaling pathway & 136 & 0.001 \\
\hline Lysosome & 119 & 0.001 \\
\hline Endometrial cancer & 52 & 0.001 \\
\hline Adipocytokine signaling pathway & 67 & 0.001 \\
\hline Apoptosis & 85 & 0.001 \\
\hline Fatty acid metabolism & 42 & 0.001 \\
\hline Sphingolipid metabolism & 36 & 0.001 \\
\hline Acute myeloid leukemia & 57 & 0.001 \\
\hline mTOR signaling pathway & 51 & 0.001 \\
\hline Prostate cancer & 88 & 0.001 \\
\hline Pathways in cancer & 324 & 0.001 \\
\hline ERBB signaling pathway & 87 & 0.001 \\
\hline Chronic myeloid leukemia & 73 & 0.001 \\
\hline Small cell lung cancer & 84 & 0.002 \\
\hline Peroxisome & 78 & 0.005 \\
\hline FC gamma $r$ mediated phagocytosis & 93 & 0.005 \\
\hline Neurotrophin signaling pathway & 126 & 0.005 \\
\hline Non-small cell lung cancer & 54 & 0.005 \\
\hline Vasopressin regulated water reabsorption & 44 & 0.005 \\
\hline Colorectal cancer & 62 & 0.005 \\
\hline Ubiquitin mediated proteolysis & 134 & 0.005 \\
\hline Amino sugar and nucleotide sugar metabolism & 44 & 0.005 \\
\hline MAPK signaling pathway & 264 & 0.005 \\
\hline Vibrio cholerae infection & 53 & 0.005 \\
\hline Fructose and mannose metabolism & 34 & 0.007 \\
\hline Glycolysis gluconeogenesis & 59 & 0.008 \\
\hline N-glycan biosynthesis & 46 & 0.008 \\
\hline Snare interactions in vesicular transport & 38 & 0.009 \\
\hline Renal cell carcinoma & 70 & 0.009 \\
\hline Focal adhesion & 199 & 0.01 \\
\hline Toll-like receptor signaling pathway & 89 & 0.013 \\
\hline Regulation of actin cytoskeleton & 210 & 0.013 \\
\hline Chemokine signaling pathway & 185 & 0.014 \\
\hline Lysine degradation & 41 & 0.014 \\
\hline Long term potentiation & 69 & 0.014 \\
\hline Pancreatic cancer & 70 & 0.014 \\
\hline Adherens junction & 73 & 0.014 \\
\hline Wnt signaling pathway & 149 & 0.014 \\
\hline Glycosaminoglycan degradation & 21 & 0.014 \\
\hline VEGF signaling pathway & 75 & 0.014 \\
\hline Valine leucine and isoleucine degradation & 44 & 0.014 \\
\hline Epithelial cell signaling in helicobacter pylori infection & 67 & 0.014 \\
\hline JAK-STAT signaling pathway & 136 & 0.017 \\
\hline NOD-like receptor signaling pathway & 61 & 0.019 \\
\hline Glioma & 65 & 0.02 \\
\hline Galactose metabolism & 25 & 0.02 \\
\hline Thyroid cancer & 29 & 0.02 \\
\hline Axon guidance & 128 & 0.022 \\
\hline FC epsilon RI signaling pathway & 78 & 0.023 \\
\hline Selenoaminoacid metabolism & 26 & 0.03 \\
\hline Betaalanine metabolism & 22 & 0.032 \\
\hline GNRH signaling pathway & 100 & 0.032 \\
\hline Glycerophospholipid metabolism & 71 & 0.032 \\
\hline Propanoate metabolism & 32 & 0.032 \\
\hline Aldosterone regulated sodium reabsorption & 41 & 0.032 \\
\hline Progesterone mediated oocyte maturation & 83 & 0.033 \\
\hline Glycerolipid metabolism & 42 & 0.033 \\
\hline Tight junction & 129 & 0.034 \\
\hline
\end{tabular}

TABLE 4 | Continued

\begin{tabular}{lcc}
\hline Name & Size & $\boldsymbol{P}$ value \\
\hline P53 signaling pathway & 66 & 0.034 \\
RIG I like receptor signaling pathway & 56 & 0.034 \\
O-glycan biosynthesis & 27 & 0.037 \\
Leukocyte transendothelial migration & 115 & 0.039 \\
Butanoate metabolism & 33 & 0.043 \\
Oocyte meiosis & 109 & 0.046 \\
\hline
\end{tabular}

respectively although spontaneous lymphomas, liver and lung cancers were detected in Becn1-/+ mice (23). Reportedly, microadenoma, macroadenoma to invasive well-differentiated adenocarcinoma were rapidly observed in the gastric Lgr5+ stem cells with the double deletion of Smad4 and PTEN using Lgr5Cre mice (46). Our findings support the opinion that Becn-1mediated gastric cancer might originate from local stem cells with genetic alteration, but not the differentiated cells. Additionally, Becn1-induced gastric carcinogenesis possibly needs the exposure to chemical carcinogen.

Bax can open the mitochondrial voltage-dependent anion channel during apoptosis, which is inhibited by interaction with $\mathrm{Bcl}-2$ on the mitochondrial membrane (47). Consequently, Bax overexpression and $\mathrm{Bcl}-2$ underexpression in gastric cancer cells may account for the inductive effect of Beclin 1 on apoptosis via mitochondrial pathway. Reportedly, activated p38 MAPK phosphorylates MAPKAP kinase 2 to phosphorylate the transcription factors (e.g. ATF2, Mac, and MEF2) and subsequently to mediate cell survival. PI3K/Akt activation results in drug resistance and cell proliferation. We observed p-p38 overexpression in Becn1-ovexpressing or silencing gastric cancer cells, but both p-PI3K and p-Akt hyperexpression was seen in Becn1-ovexpressing, but not Becn1-knockdown cells, suggesting that PI3K/Akt signal pathway might be involved in the effects of Beclin 1, but not p38. According to the literature, MDR1 and LRP1 are mainly responsible for drug resistance due to their ATPdependent efflux pumping (47). ING5 overexpression also caused chemoresistance in neuroblastoma, glioma, gastric cancer, lung cancer, ovarian cancer and breast cancer cells (48-52). Cellular stress or increased metabolic demand activates autophagy, which can cause therapeutic resistance (47). Our results hinted that the Beclin 1-mediated chemoresistance might be due to autophagy and the hyperexpression of MDR1, LRP1, and ING5. Becn1 overexpression was found to markedly attenuate the ability of gastric cancer cells to migrate and invade possibly due to VEGF hypoexpression because VEGF may promote mobility and proliferation of gastric cancer cells. In the study, E-cadherin hyperexpression, and Twist1 and Zeb2 hypoexpression in gastric Becn1 transfectants were closely linked to MET because Zeb2 and twist promote EMT process with E-cadherin underexpression. Therefore, the inhibitory of Beclin 1 on migration and invasion was dependent on MET in gastric cancer cells.

TGF- $\beta 1$-induced autophagy linked $\beta$-catenin and Smad signaling to promote EMT of mouse kidney proximal tubular epithelial C1.1 (SV40 transformed) cells by disrupting Ecadherin/ $\beta$-catenin- mediated cell-cell contact via ILK overexpression (53). SIRT1, SIRT6 and SPHK1 induced EMT 
by up-regulating autophagy-linked lysosomal degradation of Ecadherin in melanoma and hepatocellular cells via Beclin 1-Ecadherin cascade respectively (54-56). FSTL1 was demonstrated to induce EMT and airway remodeling by activating autophagy in asthma (57). HMGB1 also induced apoptosis and EMT in association with autophagy through the upregulated expression of DDR1 and the downregulation of the phosphorylation of mTOR following H/R injury in H9c2 cells (58). Persistent hypoxia induced autophage disorders, which could cause down-regulated E-cadherin and down-regulated MMP-9, thus promoting invasiveness of placenta trophoblasts (59). GRIM-19 suppressed hypoxia-triggered invasion and EMT by inhibiting hypoxia-induced autophagy through inactivation HIF-1 $\alpha$ / STAT3 signaling axis (60). HIF- $1 \alpha$-mediated autophagy promoted EMT and metastatic ability of CD133+ pancreatic cancer stem-like cells during intermittent hypoxia (61). Endoplasmic reticulum stress induced EMT through autophagy via c-src kinase activation (62). In contrast, Catalano et al. (63) reported that autophagy induction impaired migration and invasion by reversing EMT in glioblastoma cells, in line with our inductive effects of Beclin 1 overexpression on E-cadherin expression in gastric cancer. In combination of these findings, we speculated that the regulatory correlation between Beclin 1 and E-cadherin depended on the cell types.

Reportedly, loss and down-regulation of Beclin 1 expression was immunohistochemically observed in esophageal adenocarcinoma (64), colorectal cancer (65), breast cancer (66), but versa in pancreatic cancer (67). Here, we performed meta-analysis and found that down-regulated Beclin 1 expression in gastric cancer was positively linked to lymph node metastasis, TNM staging, dedifferentiation and poor prognosis, in agreement with our bioinformatics findings. Reportedly, loss of Beclin-1 in cancer cells and Beclin 1 overexpression in stromal mesenchymal cells were closely linked to local recurrence and lymph node metastasis in breast cancer (68). Beclin-1 expression was related to HBV infection status and the grade of hepatocellular carcinoma (HCC) (69). In the hypoxic group, it was negatively correlated with high tumor grade, advanced stage, large size, and multifocal tumors of HCC, while positively with TNM stage and liver metastasis of gallbladder carcinoma (70), and with worse recurrence in intrahepatic cholangiocarcinoma (71). Beclin 1 expression was reported negatively correlate with tumor grade, lymph node involvement, TNM stage, tumor size, dedifferentiation, and recurrence of lung cancer (72). These findings indicated that its down-regulation contributed to gastric carcinogenesis and progression as a molecular marker.

Becn1 expression loss was demonstrated to act as a negative prognosticator in ovarian cancer patients receiving platinum-based chemotherapy (73). Tang et al. (74) found that low Becn1 expression was associated with poor prognosis in breast cancer as an independent predictor, but the converse was true for breast cancer patients receiving tamoxifen treatment (75). Beclin 1 was considered as a dependent factor for favorable prognosis of the colorectal cancer patients (65). It was the same for ovarian clear cell carcinomas (76) and multiple myeloma (77). In contrast, Beclin 1 was significantly correlated with short disease-free survival and overall survival of pancreatic ductal adenocarcinoma (67). Here, meta- or bioinformatics analysis showed that either Beclin 1 protein or mRNA expression was positively linked to the favorable prognosis of the patients with gastric cancer. Taken together, Beclin 1 might be considered as a potential marker for the prognosis of the gastric cancer patients at either mRNA or protein level.

Down-regulated Becn 1 expression in gastric cancer was positively correlated with aggressiveness and worse prognosis at either mRNA or protein level as a molecular marker. Becn1 $\mathrm{KO}$ in pit, parietal or chief cells couldn't induce gastric carcinogenesis. It might be employed as a potential target for gene therapy of gastric cancer patients if its chemoresistant induction would be avoided and alleviated.

\section{DATA AVAILABILITY STATEMENT}

The raw data supporting the conclusions of this article will be made available by the authors, without undue reservation.

\section{ETHICS STATEMENT}

The animal study was reviewed and approved by The Affiliated Hospital of Chengde Medical University.

\section{AUTHOR CONTRIBUTIONS}

H-cZ, SZ, HX, E-hZ, H-mJ, and C-lH designed and carried out the experiments, and $\mathrm{HZ}$ wrote the draft. All authors read and approved the final manuscript. All authors contributed to the article and approved the submitted version.

\section{FUNDING}

This study was supported by Award for Liaoning Distinguished Professor, and National Natural Scientific Foundation of China (81672700).

\section{ACKNOWLEDGMENT}

Becn 1 conditional mutants were kindly presented for research by Mouse Biology Program, University of California, Davis, USA. Atp-4b-cre and Capn8-cre mice were kindly presented by Prof. Yang from the Genetic Laboratory of Development and Diseases, State Key Laboratory of Proteomics, Institute of Biotechnology, Beijing, People's Republic of China. 


\section{REFERENCES}

1. Venerito M, Link A, Rokkas T, Malfertheiner P. Gastric cancer - clinical and epidemiological aspects. Helicobacter (2016) 21(Suppl 1):39-44. doi: 10.1111/hel.12339

2. den Hoed CM, Kuipers EJ. Gastric cancer: how can we reduce the incidence of this disease? Curr Gastroenterol Rep (2016) 18(7):34. doi: 10.1007/s11894-016-0506-0

3. Sahni S, Merlot AM, Krishan S, Jansson PJ, Richardson DR. Gene of the month: BECN1. J Clin Pathol (2014) 67(8):656-60. doi: 10.1136/jclinpath-2014-202356

4. Hill SM, Wrobel L, Rubinsztein DC. Post-translational modifications of Beclin 1 provide multiple strategies for autophagy regulation. Cell Death Differ (2019) 26(4):617-29. doi: 10.1038/s41418-018-0254-9

5. Park SE, Yi HJ, Suh N, Park YY, Koh JY, Jeong SY, et al. Inhibition of EHMT2/G9a epigenetically increases the transcription of Beclin-1 via an increase in ROS and activation of NF-אB. Oncotarget (2016) 7(26):39796-808. doi: 10.18632/oncotarget.9290

6. Kang R, Zeh HJ, Lotze MT, Tang D. The Beclin 1 network regulates autophagy and apoptosis. Cell Death Differ (2011) 18(74):571-80. doi: 10.1038/cdd.2010.191

7. Fujiwara N, Usui T, Ohama T, Sato K. Regulation of Beclin 1 Protein Phosphorylation and Autophagy by Protein Phosphatase 2A (PP2A) and Death-associated Protein Kinase 3 (DAPK3). J Biol Chem (2016) 291 (20):10858-66. doi: 10.1074/jbc.M115.704908

8. Sun T, Li X, Zhang P, Chen WD, Zhang HL, Li DD, et al. Acetylation of Beclin 1 inhibits autophagosome maturation and promotes tumour growth. Nat Commun (2015) 6:7215. doi: 10.1038/ncomms8215

9. Liu H, Ma Y, He HW, Wang JP, Jiang JD, Shao RG. SLC9A3R1 stimulates autophagy via BECN1 stabilization in breast cancer cells. Autophagy (2015) 11(12):2323-34. doi: 10.1080/15548627.2015.1074372

10. Jin S, Tian S, Chen Y, Zhang C, Xie W, Xia X, et al. USP19 modulates autophagy and antiviral immune responses by deubiquitinating Beclin-1. EMBO J (2016) 35(8):866-80. doi: 10.15252/embj.201593596

11. Tang Y, Zhang Y, Liu S, Sun Z, Wang C, Li L, et al. 14-3-3 $\zeta$ binds to and stabilizes phospho-beclin 1S295 and induces autophagy in hepatocellular carcinoma cells. J Cell Mol Med (2020) 24(1):954-64. doi: 10.1111/jcmm.14806

12. Liu K, Guo C, Lao Y, Yang J, Chen F, Zhao Y, et al. A fine-tuning mechanism underlying self-control for autophagy: deSUMOylation of BECN1 by SENP3. Autophagy (2020) 16(6):975-90. doi: 10.1080/15548627.2019.1647944

13. Zhu Y, Zhao L, Liu L, Gao P, Tian W, Wang X, et al. Beclin 1 cleavage by caspase-3 inactivates autophagy and promotes apoptosis. Protein Cell (2010) 1 (5):468-77. doi: 10.1007/s13238-010-0048-4

14. Siddiqui MA, Mukherjee S, Manivannan P, Malathi K. RNase L cleavage products promote switch from autophagy to apoptosis by Caspase-mediated cleavage of Beclin-1. Int J Mol Sci (2015) 16(8):17611-36. doi: 10.3390/ijms160817611

15. Peng Y, Miao H, Wu S, Yang W, Zhang Y, Xie G, et al. ABHD5 interacts with BECN1 to regulate autophagy and tumorigenesis of colon cancer independent of PNPLA2. Autophagy (2016) 12(11):2167-82. doi: 10.1080/15548627.2016.1217380

16. Zhao Y, Chen S, Gou WF, Xiao LJ, Takano Y, Zheng HC. Aberrant Beclin 1 expression is closely linked to carcinogenesis, differentiation, progression, and prognosis of ovarian epithelial carcinoma. Tumour Biol (2014) 35(3):1955-64. doi: 10.1007/s13277-013-1261-6

17. Zhang MY, Gou WF, Zhao S, Mao XY, Zheng ZH, Takano Y, et al. Beclin 1 expression is closely linked to colorectal carcinogenesis and distant metastasis of colorectal carcinoma. Int J Mol Sci (2014) 15(8):14372-85. doi: 10.3390/ijms150814372

18. Yu M, Gou WF, Zhao S, Xiao LJ, Mao XY, Xing YN, et al. Beclin 1 expression is an independent prognostic factor for gastric carcinomas. Tumour Biol (2013) 34(2):1071-83. doi: 10.1007/s13277-013-0648-8

19. Zhang MY, Wang LY, Zhao S, Guo XC, Xu YQ, Zheng ZH, et al. Effects of Beclin 1 overexpression on aggressive phenotypes of colon cancer cells. OncolLett (2019) 17(2):2441-50. doi: 10.3892/ol.2018.9817

20. Pickford F, Masliah E, Britschgi M, Lucin K, Narasimhan R, Jaeger PA, et al. The autophagy-related protein beclin 1 shows reduced expression in early Alzheimer disease and regulates amyloid beta accumulation in mice. J Clin Invest (2008) 118(6):2190-9. doi: 10.1172/JCI33585

21. Gao P, Hao F, Dong X, Qiu Y. The role of autophagy and Beclin-1 in radiotherapy-induced apoptosis in thyroid carcinoma cells. Int J Clin Exp Pathol (2019) 12(3):885-92.

22. Furuya D, Tsuji N, Yagihashi A, Watanabe N. Beclin 1 augmented cisdiamminedichloroplatinum induced apoptosis via enhancing caspase- 9 activity. Exp Cell Res (2005) 307(1):26-40. doi: 10.1016/j.yexcr.2005.02.023
23. Qu X, Yu J, Bhagat G, Furuya N, Hibshoosh H, Troxel A, et al. Promotion of tumorigenesis by heterozygous disruption of the beclin 1 autophagy gene. J Clin Invest (2003) 112(12):1809-20. doi: 10.1172/JCI20039

24. Yue Z, Jin S, Yang C, Levine AJ, Heintz N. Beclin 1, an autophagy gene essential for early embryonic development, is a haploinsufficient tumor suppressor. Proc Natl Acad Sci USA (2003) 100(25):15077-82. doi: 10.1073/ pnas. 2436255100

25. Won KY, Kim GY, Lim SJ, Sung JY, Kim YW, Park YK, et al. Autophagy is related to the hedgehog signaling pathway in human gastric adenocarcinoma: prognostic significance of Beclin -1 and Gli2 expression in human gastric adenocarcinoma. Pathol Res Pract (2015) 211(4):308-15. doi: 10.1016/ j.prp.2014.11.005

26. Geng QR, Xu DZ, He LJ, Lu JB, Zhou ZW, Zhan YQ, et al. Beclin-1 expression is a significant predictor of survival in patients with lymph node-positive gastric cancer. PloS One (2012) 7(9):e45968. doi: 10.1371/journal.pone.0045968

27. Chen YB, Hou JH, Feng XY, Chen S, Zhou ZW, Zhang XS, et al. Decreased expression of Beclin 1 correlates with a metastatic phenotypic feature and adverse prognosis of gastric carcinomas. J Surg Oncol (2012) 105(6):542-7. doi: $10.1002 /$ jso. 22151

28. Fei B, Ji F, Chen X, Liu Z, Li S, Mo Z, et al. Expression and clinical significance of Beclin-1 in gastric cancer tissues of various clinical stages. Oncol Lett (2016) 11(3):2271-7. doi: 10.3892/ol.2016.4183

29. Qin W, Li C, Zheng W, Guo Q, Zhang Y, Kang M, et al. Inhibition of autophagy promotes metastasis and glycolysis by inducing ROS in gastric cancer cells Oncotarget (2015) 6(37):39839-54. doi: 10.18632/oncotarget.5674

30. Zhou WH, Tang F, Xu J, Wu X, Yang SB, Feng ZY, et al. Low expression of Beclin 1, associated with high $\mathrm{Bcl}-\mathrm{xL}$, predicts a malignant phenotype and poor prognosis of gastric cancer. Autophagy (2012) 8(3):389-400. doi: 10.4161/auto.18641

31. Yu S, Li G, Wang Z, Wang Z, Chen C, Cai S, et al. Low expression of MAP1LC3B, associated with low Beclin-1, predicts lymph node metastasis and poor prognosis of gastric cancer. Tumour Biol (2016) 37(11):15007-17. doi: 10.1007/s13277-016-5383-5

32. Zhao Z, Han F, Yang S, Wu J, Zhan W. Oxamate-mediated inhibition of lactate dehydrogenase induces protective autophagy in gastric cancer cells: involvement of the Akt-mTOR signaling pathway. Cancer Lett (2015) 358 (1):17-26. doi: 10.1016/j.canlet.2014.11.046

33. Qiu G, Li X, Wei C, Che X, He S, Lu J, et al. The prognostic role of SIRT1autophagy axis in gastric cancer. Dis Markers (2016) 2016:6869415. doi: $10.1155 / 2016 / 6869415$

34. Cao QH, Liu F, Yang ZL, Fu XH, Yang ZH, Liu Q, et al. Prognostic value of autophagy related proteins ULK1, Beclin 1, ATG3, ATG5, ATG7, ATG9, ATG10, ATG12, LC3B and p62/SQSTM1 in gastric cancer. Am J Transl Res (2016) 8(9):3831-47.

35. Huang JL, Zhong TM, Huang ZS, Li GZ, Zhou XH, He SG, et al. Correlation study of expression of autophagic factors Beclin 1 and LC3 and clinicopathological features in gastric cancer. Pract J Cancer (2016) 31:530-2.

36. Hu YF, Lei X, Zhao H, Yang WW, Feng XM, Yin XL, et al. The association of expressions of autophagy-related protein Beclin 1 and HP infection in gastric cancer. Modern Oncol (2017) 25:1093-6.

37. Guo CQ, Shao JH, Lu RL, Cao XG. Expression of Beclin 1 and PTEN proteins in gastric cancer tissues. J Zhengzhou Univ (Med Sci) (2010) 45(3):463-5.

38. Zhang Y, Lin S, Zhang Y, Chang S. Effect of beclin 1 expression on the biological behavior and chemotherapy sensitivity of cervical cancer cells. Oncol Lett (2016) 11(6):4089-94. doi: 10.3892/ol.2016.4542

39. Wang W, Fan H, Li X, Wu G, Zhao W, Zhang G, et al. Beclin 1 promotes apoptosis and decreases invasion by upregulating the expression of ECRG4 in A549 human lung adenocarcinoma cells. Mol Med Rep (2016) 14(1):355-60. doi: $10.3892 / \mathrm{mmr} .2016 .5219$

40. Wang MC, Wu AG, Huang YZ, Shao GL, Ji SF, Wang RW, et al. Autophagic regulation of cell growth by altered expression of Beclin 1 in triple-negative breast cancer. Int J Clin Exp Med (2015) 8(5):7049-58.

41. Li S, Zhang HY, Du ZX, Li C, An MX, Zong ZH, et al. Induction of epithelialmesenchymal transition (EMT) by Beclin 1 knockdown via posttranscriptional upregulation of ZEB1 in thyroid cancer cells. Oncotarget (2016) 7(43):70364-77. doi: 10.18632/oncotarget.12217

42. Shu CW, Chang HT, Wu CS, Chen CH, Wu S, Chang HW, et al. RelAmediated BECN1 expression is required for reactive oxygen species-induced autophagy in oral cancer cells exposed to low-power laser irradiation. PloS One (2016) 11(9):e0160586. doi: 10.1371/journal.pone.0160586 
43. Hasan A, Haque E, Hameed R, Maier PN, Irfan S, Kamil M, et al. Hsp90 inhibitor gedunin causes apoptosis in A549 lung cancer cells by disrupting Hsp90: Beclin-1:Bcl-2 interaction and downregulating autophagy. Life Sci (2020) 256:118000. doi: 10.1016/j.lfs.2020.118000

44. Hu F, Li G, Huang C, Hou Z, Yang X, Luo X, et al. The autophagyindependent role of BECN1 in colorectal cancer metastasis through regulating STAT3 signaling pathway activation. Cell Death Dis (2020) 11 (5):304. doi: 10.1038/s41419-020-2467-3

45. Cheng Z, Xin H, Han T. BECN1 promotes the migration of NSCLC cells through regulating the ubiquitination of Vimentin. Cell Adh Migr (2019) 13 (1):249-59. doi: 10.1080/19336918.2019.1638690

46. Li XB, Yang G, Zhu L, Tang YL, Zhang C, Ju Z, et al. Gastric Lgr5(+) stem cells are the cellular origin of invasive intestinal-type gastric cancer in mice. Cell Res (2016) 26(7):838-49. doi: 10.1038/cr.2016.47

47. Zheng HC. The molecular mechanisms of chemoresistance in cancers. Oncotarget (2017) 8(35):59950-64. doi: 10.18632/oncotarget.19048

48. Zheng HC, Zhao S, Song Y, Ding XQ. The roles of ING5 expression in ovariancarcinogenesis and subsequent progression: a target of gene therapy. Oncotarget (2017) 8(61):103449-64. doi: 10.18632/oncotarget.21968

49. Wu JC, Jiang HM, Yang XH, Zheng HC. ING5-mediated antineuroblastoma effects ofsuberoyl- anilide hydroxamic acid. Cancer Med (2018) 7(9):4554-69. doi: $10.1002 / \mathrm{cam} 4.1634$

50. Ding XQ, Zhao S, Yang L, Zhao X, Zhao GF, Zhao SP, et al. The nucleocytoplasmic translocation and up-regulation of ING5 protein in breastcancer: a potential target for gene therapy. Oncotarget (2017) 8 (47):81953-66. doi: 10.18632/oncotarget.17918

51. Zhao S, Zhao ZJ, He HY, Wu JC, Ding XQ, Yang L, et al. The roles of ING5 in gliomas: a good marker for tumorigenesis and a potential target for gene therapy. Oncotarget (2017) 8(43):56558-68. doi: 10.18632/oncotarget.17802

52. Zhao S, Yang XF, Shen DF, Gao Y, Shi S, Wu JC, et al. The down-regulated ING5 expression in lung cancer: a potential target of genetherapy. Oncotarget (2016) 7(34):54596-615. doi: 10.18632/oncotarget.10519

53. Pang M, Wang H, Rao P, Zhao Y, Xie J, Cao Q, et al. Autophagy links $\beta$ catenin and Smad signaling to promote epithelial-mesenchymal transition via upregulation of integrin linked kinase. Int J Biochem Cell Biol (2016) 76:12334. doi: 10.1016/j.biocel.2016.05.010

54. Sun T, Jiao L, Wang Y, Yu Y, Ming L. SIRT1 induces epithelial-mesenchymal transition by promoting autophagic degradation of E-cadherin in melanoma cells. Cell Death Dis (2018) 9(2):136. doi: 10.1038/s41419-017-0167-4

55. Han LL, Jia L, Wu F, Huang C. Sirtuin6 (SIRT6) promotes the EMT of hepatocellular carcinoma by stimulating autophagic degradation of Ecadherin. Mol Cancer Res (2019) 17(11):2267-80. doi: 10.1158/15417786.MCR-19-0321

56. Liu H, Ma Y, He HW, Zhao WL, Shao RG. SPHK1 (sphingosine kinase 1) induces epithelial- mesenchymal transition by promoting the autophagylinked lysosomal degradation of $\mathrm{CDH} 1 /$ E-cadherin in hepatoma cells. Autophagy (2017) 13(5):900-13. doi: 10.1080/15548627.2017.1291479

57. Liu T, Liu Y, Miller M, Cao L, Zhao J, Wu J, et al. Autophagy plays a role in FSTL1-induced epithelial mesenchymal transition and airway remodeling in asthma. Am J Physiol Lung Cell Mol Physiol (2017) 313(1):L27-40. doi: 10.1152/ajplung.00510.2016

58. Ouyang F, Huang H, Zhang M, Chen M, Huang H, Huang F, et al. HMGB1 induces apoptosis and EMT in association with increased autophagy following $\mathrm{H} / \mathrm{R}$ injury in cardiomyocytes. Int J Mol Med (2016) 37(3):679-89. doi: 10.3892/ijmm.2016.2474

59. Chen Y, Wang L, Bao J, Sha X, Cui L, Huang Q, et al. Persistent hypoxia induced autophagy leading to invasiveness of trophoblasts in placenta accreta. J Matern Fetal Neonatal Med (2019) 3:1-7. doi: 10.1080/14767058.2019.1635582

60. Zhang J, Chu D, Kawamura T, Tanaka K, He S. GRIM-19 repressed hypoxiainduced invasion and EMT of colorectal cancer by repressing autophagy through inactivation of STAT3/HIF-1 $\alpha$ signaling axis. J Cell Physiol (2019) 234(8):12800-808. doi: 10.1002/jcp.27914

61. Zhu H, Wang D, Zhang L, Xie X, Wu Y, Liu Y, et al. Upregulation of autophagy by hypoxia-inducible factor- $1 \alpha$ promotes EMT and metastatic ability of CD133+ pancreatic cancer stem-like cells during intermittent hypoxia. Oncol Rep (2014) 32(3):935-42. doi: 10.3892/or.2014.3298

62. Moon SY, Kim HS, Nho KW, Jang YJ, Lee SK. Endoplasmic reticulum stress induces epithelial- mesenchymal transition through autophagy via activation of c-Src kinase. Nephron Exp Nephrol (2014) 126(3):127-40. doi: 10.1159/ 000362457

63. Catalano M, D’Alessandro G, Lepore F, Corazzari M, Caldarola S, Valacca C, et al. Autophagy induction impairs migration and invasion by reversing EMT in glioblastoma cells. Mol Oncol (2015) 9(8):1612-25. doi: 10.1016/ j.molonc.2015.04.016

64. Weh KM, Howell AB, Kresty LA. Expression, modulation, and clinical correlates of the autophagy protein Beclin-1 in esophageal adenocarcinoma. Mol Carcinog (2016) 55(11):1876-85. doi: 10.1002/mc.22432

65. Liu L, Meng T, Wang QS, Jin HZ, Sun ZQ, Jin B, et al. Association of Beclin-1 and microRNA-30a expression with the severity and treatment response of colorectal cancer. Genet Mol Res (2016) 15(2):15027704. doi: 10.4238/ gmr.15027704

66. Wu T, Li Y, Gong L, Lu JG, Du XL, Zhang WD, et al. Multi-step process of human breast carcinogenesis: a role for BRCA1, BECN1, CCND1, PTEN and UVRAG. Mol Med Rep (2012) 5(2):305-12. doi: 10.3892/mmr.2011.634

67. Song S, Wang B, Gu S, Li X, Sun S. Expression of Beclin 1 and Bcl-2 in pancreatic neoplasms and its effect on pancreatic ductal adenocarcinomaprognosis. Oncol Lett (2017) 14(6):7849-61. doi: 10.3892/ ol.2017.7218

68. Morikawa A, Takeuchi T, Kito Y, Saigo C, Sakuratani T, Futamura M, et al. Expression of beclin-1 in the microenvironment of invasive ductal carcinoma of the breast: correlation with prognosis and the cancer-stromal interaction. PloS One (2015) 10(5):e0125762. doi: 10.1371/journal.pone.0125762

69. Qin Z, Yu X, Lin M, Wu J, Ma S, Wang N. Prognostic and clinicopathologicalvalue of Beclin-1 expression in hepatocellular carcinoma: a meta-analysis. World J Surg Oncol (2018) 1(1):170. doi: 10.1186/s12957018-1465-8

70. Chen Y, Yan J, Yu S, Wang X, Zheng Q. Over-expression of beclin-1 in gallbladder carcinoma and its relationship with prognosis. Contemp Oncol (Pozn) (2014) 18(3):171-6. doi: 10.5114/wo.2014.41395

71. Bi C, Liu M, Rong W, Wu F, Zhang Y, Lin S, et al. High Beclin-1 and ARID1A expression corelates with poor survival and high recurrence in intrahepatic cholangiocarcinoma: a histopathological retrospective study. BMC Cancer (2019) 19:213. doi: 10.1186/s12885-019-5429-3

72. Zheng T, Li D, He Z, Feng S, Zhao S. Prognostic and clinicopathological significance of Beclin-1 in non-small-cell lung cancer: a meta-analysis. OncoTargets Ther (2018) 11:4167-75. doi: 10.2147/OTT.S164987

73. Minamoto T, Nakayama K, Nakamura K, Katagiri H, Sultana R, Ishibashi T, et al. Loss of beclin 1 expression in ovarian cancer: A potential biomarker for predicting unfavorable outcomes. Oncol Lett (2018) 15(1):1170-6. doi: 10.3892/ol.2017.7379

74. Tang H, Sebti S, Titone R, Zhou Y, Isidoro C, Ross TS, et al. Decreased BECN1 mRNA expression in human breast cancer is associated with estrogen receptor-negative subtypes and poor prognosis. EbioMedicine (2015) 2 (3):255-63. doi: 10.1016/j.ebiom.2015.01.008

75. Gu Y, Chen T, Li G, Xu C, Xu Z, Zhang J, et al. Lower Beclin 1 downregulates HER2 expression to enhance tamoxifen sensitivity and predicts a favorable outcome for ER positive breast cancer. Oncotarget (2016) 8(32):52156-77. doi: 10.18632/oncotarget.11044

76. Katagiri H, Nakayama K, Razia S, Nakamura K, Sato E, Ishibashi T, et al. Loss of autophagy-related protein Beclin 1 may define poor prognosis in ovarian clear cell carcinomas. Int J Oncol (2015) 47(6):2037-44. doi: 10.3892/ ijo. 2015.3191

77. Jung G, Roh J, Lee H, Gil M, Yoon DH, Suh C, et al. Autophagic markers BECLIN 1 and LC3 are associated with prognosis of multiple myeloma. Acta Haematol (2015) 134(1):17-24. doi: 10.1159/000368848

Conflict of Interest: The authors declare that the research was conducted in the absence of any commercial or financial relationships that could be construed as a potential conflict of interest.

Copyright (c) 2020 Zheng, Zhao, Xue, Zhao, Jiang and Hao. This is an open-access article distributed under the terms of the Creative Commons Attribution License (CC BY). The use, distribution or reproduction in other forums is permitted, provided the original author(s) and the copyright owner(s) are credited and that the original publication in this journal is cited, in accordance with accepted academic practice. No use, distribution or reproduction is permitted which does not comply with these terms. 